\title{
Tarzan swings: a dangerous new epidemic
}

\author{
D. J. Edwards FRCS \\ Orthopaedic Registrar, Sheffield Children's Hospital, Sheffield, UK
}

Accidental injury in school children was thought to be unpreventable. This series presents the results of 24 consecutive patients with 29 fractures as a result of a fall from a 'Tarzan' rope swing. Twenty-six of the fractures involved the upper limb, 11 patients required hospitalization with operative intervention and 13 required outpatient care only. These types of injury are preventable. The morbidity and pain that these young patients suffer can be avoided.

Keywords: Tarzan swing

Accidents are the most common cause of morbidity in children: $25 \%$ of deaths and $20 \%$ of hospital admissions are a direct result of accidents ${ }^{1,2}$. Of these accidents, $49 \%$ occur outdoors and $35 \%$ are due to a fall. This series presents 24 consecutive patients with 29 fractures following a fall from a Tarzan swing (Figure 1). The patients, types of fractures sustained, method of treatment and period of hospitalization are discussed.

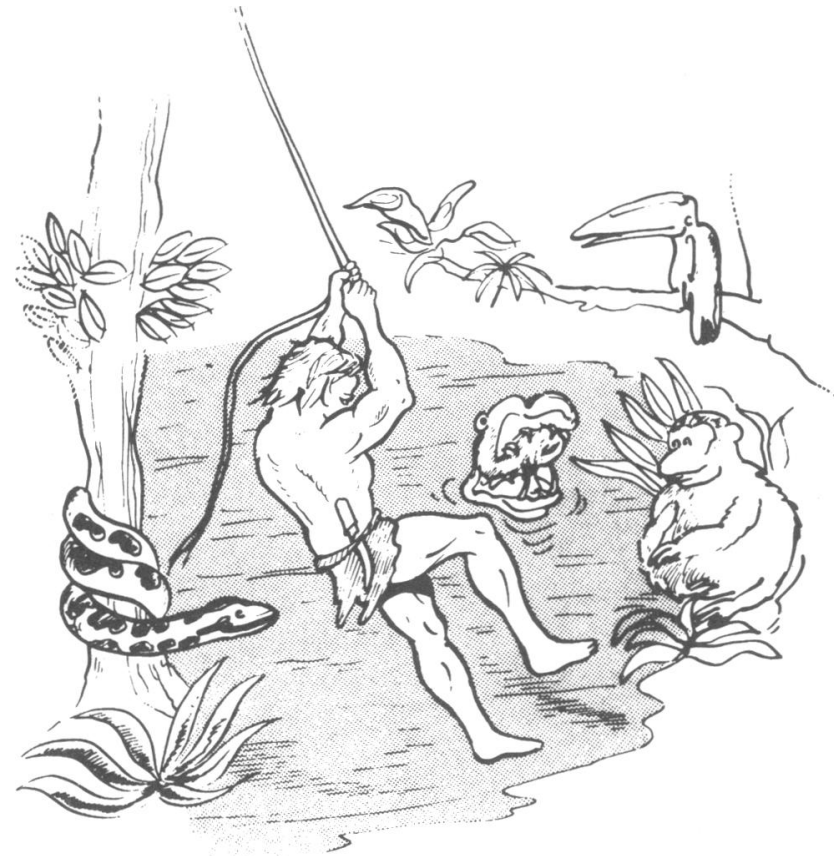

Figure 1. Tarzan swing

Address for correspondence: D. J. Edwards, 4 Nook Lane, Stannington, Sheffield S6 6BN, UK

(C) 1991 Butterworth-Heinemann Ltd. 0306-3674/91/030168-02

\section{Patients and results}

All fractures were sustained during July 1989 in Sheffield. There were 16 boys and eight girls (Figure 2) aged from 8 to 15 years (mean 11.42). All patients were seen on the day of the accident or in the subsequent fracture clinic by the author.

Of the 29 fractures, $26(90 \%)$ involved the upper limb. Eighteen fractures involved the wrist (Figure 3).

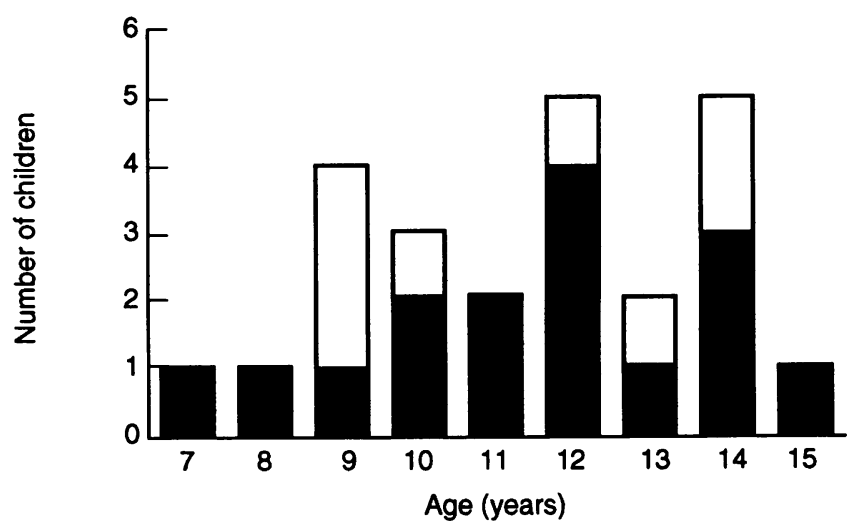

Figure 2. Age and sex distribution. $\square$, Girls; $\square$, boys

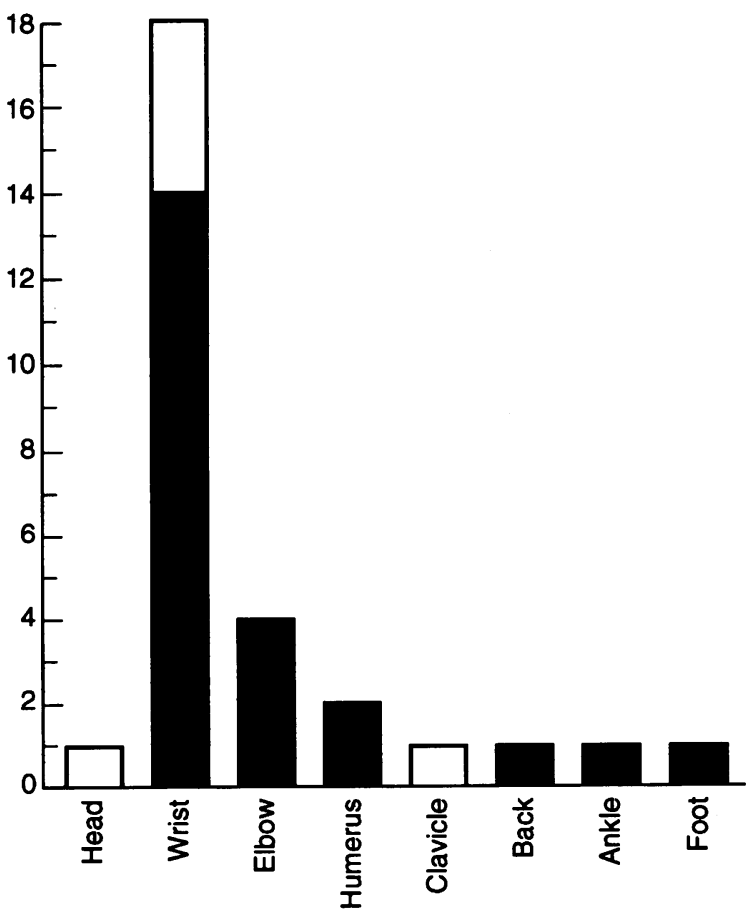

Figure 3. Location of fractures. $\square$, Girls; $\square$, boys 
Two children sustained bilateral fractures of the distal radius and ulna and one child sustained fractures of the wrist, the second lumbar vertebra and the fifth metatarsal. Ten of the 16 boys required hospitalization; the average stay was 3.4 days (range $1-10$ ).

Of the 21 fractures in the male group, 12 needed manipulation, two internal fixation (one failed manipulation), one fasciotomy for a forearm compartment syndrome and eight required plaster of Paris immobilization only.

Only one of the eight girls needed manipulation of her fracture, the remainder requiring outpatient care only.

\section{Discussion}

Accidental injuries have been thought to be largely unpreventable ${ }^{13}$. Stanley and Bell questioned this and suggested that improved supervision might reduce the frequency of certain accidents ${ }^{4}$.

In Stanley and Bell's series, 11 of 123 fractures over 6 months were caused by a fall from a rope swing.
These rope swings are often erected by the child but in some cases, adults will help in their placement. In this series there was no one notorious swing but all were characteristically positioned over a large drop (in one case this was over a rocky river-bed some 20 feet below!).

The frequency of injuries from rope swings appears to be increasing. The morbidity and psychological distress to the child can not be measured. Children will always take risks, but, with a little thought by the parents or education of the at-risk group, these unnecessary accidents can be avoided.

\section{References}

1 Jackson RH, Wilkinson AW. Why don't we prevent childhood accidents? Br Med J 1976; i: 1258-62.

2 Illingworth CM. 227 road accidents to children. Acta Paediatr Scand 1979; 68: 869-73.

3 Sibert JR, Maddocks GB, Brown BM. Childhood accidents-an endemic of epidemic proportions. Arch Dis Child 1981; 56: 225-34.

4 Stanley D, Bell MJ. Forearm fractures in schoolchildren. Br Med $J$ 1989; 298: 1159-60. 